\title{
Cervical spine involvement in patients with juvenile idiopathic arthritis - MRI follow-up study
}

\author{
Toni Hospach ${ }^{1 *}$, Jan Maier ${ }^{1}$, Peter Müller-Abt ${ }^{2}$, Anita Patel ${ }^{1}$, Gerd Horneff $^{3}$ and Thekla von Kalle ${ }^{2}$
}

\begin{abstract}
Background: To describe MRI and clinical findings in patients with juvenile idiopathic arthritis with cervical spine involvement at onset and follow-up under therapy.

Methods: 13 patients with signs of cervical spine involvement in juvenile idiopathic arthritis with a median disease duration of 1.7 years were included in the study. Clinical records and MR images were retrospectively analyzed according to symptoms and findings concerning the cervical spine.

Results: At the onset of cervical spine involvement all patients showed limited range of motion, whereas only 5 of them complained of pain. In MR images joint hyperintensity, contrast enhancement, malalignment, ankylosis, erosion and narrowing of the spinal canal at cranio-cervical junction were found at 28, 32, 15, 2, 2 and 3 sites in 12 (93\%), 13 (100\%), 8 (62\%), 2 (15\%), 2 and 3 (20\%) patients respectively. 3 of the 5 patients with pain (60\%) showed ankylosis, erosions or narrowing of the spinal canal at cranio-cervical junction on MRI. At follow-up - after a median disease duration of cervical spine arthritis of 2.1 years and a variable duration of treatment with methotrexate (all patients) and biological agents (12 patients) - joint hyperintensity, enhancement and malalignment decreased to 15, 19 and 6 sites in 10 (77\%), 11 (85\%) and 3 (20\%) patients respectively whereas ankylosis, erosion and narrowing of the spinal canal at cranio-cervical junction increased to 7, 6 and 4 sites in $3(20 \%), 4(31 \%)$ and 4 patients respectively. Pain was no longer reported, but 9 of 13 (69\%) patients still had a limited range of motion with 6 of them (46\%) showing skeletal changes on MRI.

Conclusions: This first MRI based follow-up study shows that cervical spine arthritis can follow a severe disease course in juvenile arthritis. While malalignments and inflammation sites decreased osseous changes with erosions, ankylosis, and narrowing of the spinal canal increased under treatment despite only minor subjective complaints. Therefore close MRI monitoring of these patients appears to be reasonable.
\end{abstract}

\section{Background}

In contrast to adult rheumatoid arthritis, where numerous studies have shown a high prevalence of involvement of the cervical spine, few studies have been published examining this entity in juvenile idiopathic arthritis (JIA) [1-8]. Nearly all of the studies have used conventional radiographs as the diagnostic standard [9-13]. In a comparative study [14] magnetic-resonance imagining (MRI) showed a higher sensitivity than plain radiographs and computed tomography in diagnosing cervical spine arthritis, but reports on cross-sectional

\footnotetext{
* Correspondence: a.hospach@klinikum-stuttgart.de

'Division of Pediatric Rheumatology, Children's Hospital, Olgahospital Stuttgart, teaching hospital of the University of Tuebingen, Bismarckstr. 8, 70176 Stuttgart, Germany

Full list of author information is available at the end of the article
}

MRI findings in JIA with cervical spine involvement are rare $[15,16]$. Follow-up studies combining clinical and MRI findings are not reported for cervical spine arthritis. Only one recent study followed clinical disease activity and MRI findings of knee involvement in JIA [17] and in conclusion recommended MRI as a responsive outcome measure to evaluate disease activity.

The aim of our retrospective study was to describe and compare MRI and clinical findings at the onset and follow-up of cervical spine arthritis in JIA patients.

\section{Methods}

We searched our clinical records and radiological data base for patients with cervical spine arthritis in JIA and included patients who had both clinical and MRI examination at the onset of signs or symptoms of cervical 
spine arthritis (limited range of motion and/or pain) and at follow-up. Our search criteria were limited to individuals who had follow-up examinations between 1.1.2010 and 31.12.2011. All MR examinations were performed with a 12-channel head coil and a dedicated neck coil at 1.5 T (Magnetom Avanto Siemens Healthcare, Erlangen, Germany). Sequences were $3 \mathrm{~mm}$ sagittal and coronal short Tau inversion recovery (STIR) and T1 fat saturated dynamic imaging after injection of contrast medium with $30 \mathrm{sec}$. temporal resolution followed by a 3D T1 sequence with water excitation (fat suppression technique) in $1 \mathrm{~mm}$ sagittal partitions and high in-plane resolution; image parameters see Table 1 . Two pediatric radiologists with more than 10 years experience independently assessed MR images of the cranio-cervical junction and the cervical spine for abnormally high signal intensity of joints, bone marrow and soft tissue before and after contrast enhancement. Form, contour and alignment of the cranio-cervical junction and the cervical spine were evaluated to detect deformities, ankyloses and malpositions. All patients and their parents gave written informed consent to the examination. The retrospective evaluation of anonymized data is in accordance with the regulations of the local ethics committee. No magnetic resonance images were acquired for the study purposes.

Proposals for measurement of atlanto-axial dislocations had been derived from plain radiographs in adults and were not applicable to our cohort $[18,19]$. We therefore matched images of children who had been examined for reasons other than diseases with joint or spine involvement for age and used them as normal controls.

We defined malalignment as any abnormal (or partially abnormal) position of articular surfaces of atlantooccipital, atlanto-axial or cervical facet joints, or of two vertebrae with respect to each other (Figure 1). This definition included joint subluxation. We defined ankylosis as osseous bridges between two or more bones which are normally separate (Figure 2). An erosion is an interruption of the osseous joint surface with signs of inflammation such as a hyperintense signal in STIR images before and in T1 images after contrast injection (Figure 1). Narrowing of the spinal canal at the craniocervical junction caused by hypertrophy of the dens was assessed by comparing the sagittal diameter of the spinal

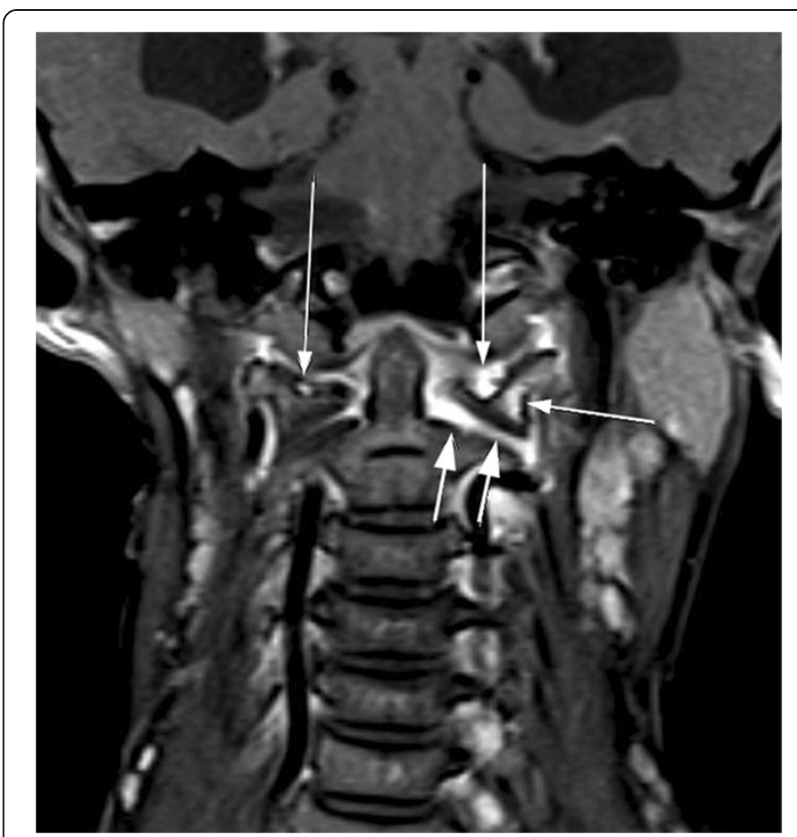

Figure 19 -year-old girl with JIA at first diagnosis of cervical arthritis ( $3 \mathrm{~mm}$ coronal T1 spinecho sequence with fat saturation). Malalignment of occiput, atlas and axis. Contrast enhancement of atlanto-occipital joints with a small erosion of the right and a large erosion of the left lateral mass of the atlas (long arrows). Contrast enhancement of the bone marrow in the atlas (short arrow). Contrast enhancement of the widened left atlanto-axial joint (two short arrows).

canal at the cranio-cervical junction to its diameter in the upper cervical spine and then to the reference image (Figure 3). We considered contrast enhancement of a joint space as sign of arthritis (synovial hypertrophy and/or pannus) aware that it may not be differentiated from diffusion of contrast material into the joint fluid (Figure 1).

All patients underwent a detailed clinical assessment including history and thorough rheumatological examination with a complete examination of all joints. As the diagnostic utility and reliability of clinical assessment of the cervical joints are known to be variable and lacking inter-observer agreement [20,21], we defined loss of range of motion as: (1) asymmetry of movement, (2) less

Table 1 Image parameters

\begin{tabular}{|c|c|c|c|c|c|c|c|}
\hline Sequence & Contrast material & TR (msec) & TE (msec) & TI (msec) & Voxel size (mm) & Coil & Other parameters \\
\hline STIR 2D coronal & Pre-contrast & $5300-6200$ & 60 & 135 & $0.4-0.8 \times 0.6-1.2 \times 3.0$ & Head coil & \\
\hline STIR 2D sagittal & Pre-contrast & 3900 & 60 & 135 & $0.4 \times 0.4 \times 3.0$ & Ring coil & \\
\hline $\begin{array}{l}\text { T1 gradient echo } \\
\text { 3D VIBE axial }\end{array}$ & $\begin{array}{l}\text { Contrast-enhanced } \\
\text { Dynamic scanning }\end{array}$ & 5.0 & 1.4 & - & $0.8 \times 0.6 \times 2.0$ & Head coil & $\begin{array}{l}\text { Fat saturation. Duration } 0.5 \mathrm{~min} \text {. } \\
\text { k-space-center at } 0.16 \mathrm{~min} \text {. }\end{array}$ \\
\hline $\begin{array}{l}\text { T1 gradient echo } \\
\text { 3D sagittal }\end{array}$ & Post-contrast & $400-630$ & $11-20$ & - & $0.5 \times 0.5 \times 1.0$ & Head coil & Water excitation \\
\hline
\end{tabular}




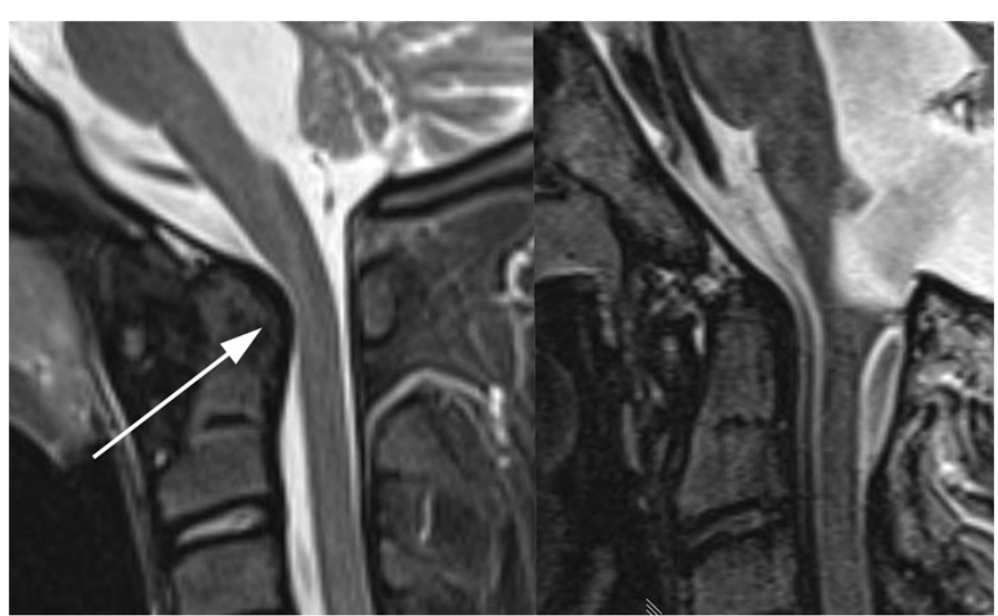

Figure 2 Left: 13-year-old girl with JIA. STIR 3 mm sagittal. Enlarged dens with bulging dorsal contour (arrow) and narrowing of the spinal canal at the cranio-cervical junction (arrowheads). Right: Normal control. 13-year-old boy without JIA and normal size of his dens.

than 90 degrees rotation or extension and/or (3) less than 45 degrees of active or passive flexion.

\section{Results}

During the study period 19 JIA patients with cervical symptoms were examined through MRI. 6 patients (3

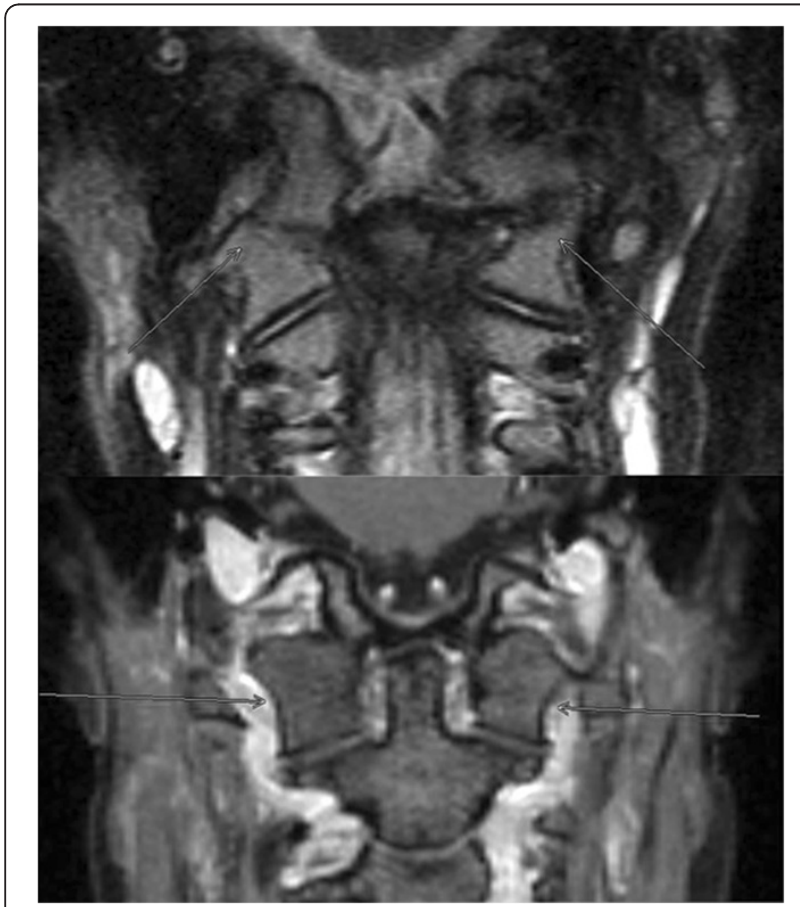

Figure 3 Two patients with ankylosis. Above: 9-year-old boy (3 mm coronal STIR). Ankylosis with partial fusion of the occipital condyle and atlas on the right with a blurring of the osseous contours on the left. Below: 17-year-old girl with bilateral complete fusion of occipital condyle and atlas (1 $\mathrm{mm}$ coronal reconstruction from high-resolution 3D T1 gradient echo post-contrast). with seronegative polyarticular JIA, 3 with extended oligoarthritis) were excluded for a missing second (followup) MRI examination. The MRIs of these patients all showed joint hyperintensity and enhancement, with malalignment in 2 of them, and none showing ankylosis, erosion or narrowing of the spinal canal at the craniocervical junction. The remaining 13 patients ( 7 females) met the inclusion criteria of clinically and radiologically documented cervical spine arthritis by at least two examinations. Median age at onset of JIA was 6 years (range 1.5 - 12), median age at diagnosis of cervical spine arthritis was 7.7 years (range 1.8 - 14), indicating a median disease duration of 1.7 years until the manifestation of cervical spine arthritis. According to ILAR classification criteria for juvenile idiopathic arthritis [22] patients were diagnosed as extended oligoarthritis (6 patients), seronegative polyarthritis (4 patients), psoriasis arthritis (2 patients), systemic arthritis (1 patient). ANA, HLA-B 27, rheumafactor positivity was seen in 8,1 and no patients respectively.

At diagnosis of cervical spine arthritis spontaneously reported pain, torticollis, limited range of motion (LROM) were noted in 5, 4, 13 patients respectively. Median duration of treatment with nonsteroidal anti-inflammatory drugs (NSAID), systemic and intraarticular steroids and methotrexate prior to diagnosis of cervical spine arthritis by first MRI patients was 1 year (range $0-11$ years). In the course of their disease, patients were treated with the following non-biological agents: NSAIDs (13), glucocorticoids (either methylprednisolon pulses or prednisolon) (13) and methotrexate (13). 12 (93\%) patients were treated with the following biologicals: etanercept (11), adalimumab (5), tocilizumab (2). 4 (31\%) of the patients had received two different biologicals, and $2(15 \%)$ patients three biologicals. Therapy was changed in 9 of our 13 patients 
due to first MRI images with seven of them receiving additional biological agents. The median duration of biological therapy was 2.5 years (range: $0.7-8$ years). Physiotherapy was conducted in all patients.

At follow-up, after a median disease duration of 2.1 years (range 0.5-8) since the first diagnosis of cervical spine symptoms, clinical assessment revealed fewer patients with spontaneous reported pain and torticollis, although the frequency of loss in range of motion was slightly decreased to 9 patients. 11 patients were still being treated for JIA while 2 patients were in remission and off medication. The median number of extraspinal arthritic joints also had decreased (Table 2).

\section{MRI findings}

Tables 3 and 4 show the analysis of the MRI findings: Table 3 indicates the number of involved sites per specific MRI finding. Table 4 indicates the number of patients showing specific MRI findings at the various sites. In most patients multiple sites were involved.

At the time of diagnosis atlanto-axial (AA) and atlanto-dental (AD) joints were most frequently affected as shown by joint hyperintensity and gadolinium enhancement. Altogether 12 (93\%) of our patients showed a hyperintense STIR signal and all 13 showed joint enhancement (Table 4).

Erosions were only seen in the dens and atlas (example see Figure 1). Narrowing of cervical spine at the craniocervical junction (CCJ) was diagnosed where hypertrophy of the dens was seen (example see Figure 2). Ankylosis (Figure 3) and erosions were seen at 7 sites in 3 patients, and 6 sites in 4 patients at follow-up indicating that these changes may occur at multiple sites in the same patient. Whereas the number of affected patients and sites with joint hyperintensity, enhancement and malalignment decreased at follow-up, ankylosis, erosions and narrowing of the spinal canal at the CCJ increased (Tables 3 and 4).

Figure 3. Two patients with ankylosis. Above: 9-yearold boy ( $3 \mathrm{~mm}$ coronal STIR). Ankylosis with partial

Table 2 Clinical characteristics at diagnosis of cervical spine arthritis and follow-up*

\begin{tabular}{lcc}
\hline Clinical characteristic & At diagnosis & At follow-up \\
\hline Spontaneous pain (no. patients) & 5 & 0 \\
Torticollis (no. patients) & 4 & 2 \\
LROM $^{* *}$ (no. patients) & 13 & 9 \\
ESR mm/1 hr. median (range) & $25(10-60)$ & $10(5-35)$ \\
Arthritis in extraspinal joints, median & $4(0-40)$ & $0(0-35)$ \\
number of joints (range) & &
\end{tabular}

*After a median duration of 2.1 years (range $0.5-8$ years) of cervical spine arthritis.

${ }^{* *}$ All of them showed asymmetry of cervical spine movement. Abbr.: $L R O M$ limited range of motion. fusion of the occipital condyle and atlas on the right with a blurring of the osseous contours on the left. Below: 17-year-old girl with bilateral complete fusion of occipital condyle and atlas $(1 \mathrm{~mm}$ coronal reconstruction from high-resolution 3D T1 gradient echo postcontrast).

\section{Associations between clinical and MRI findings}

At time of diagnosis all 13 patients showed LROM by asymmetry of cervical movements. 5 patients complained of pain with 3 of them showing ankylosis, erosions or narrowing of CCJ on MRI. At follow-up, 9 (69\%) patients showed a LROM (again all realized through the asymmetry of movements) and none complained of pain. 6 $(46 \%)$ had ankylosis, erosions or narrowing of the spinal canal, all of whom also had a LROM, and two had torticollis. 6 patients were treated with tumor necrosis factor alpha inhibitors including 3 patients who received 2 or more different agents.

\section{Discussion}

MRI allows the direct visualization of synovitis and joint effusion, it shows bone marrow edema and erosions before they become visible on radiographs. Especially in joints that are not accessible to sonography, it is therefore most suitable to detect early signs of arthritis [23]. To date there are no studies documenting the clinical course and MRI follow-up of cervical spine arthritis in JIA. However, this specific manifestation of JIA is important to monitor as it may lead to permanent restriction of cervical spine movements and may considerably impair a patient's quality of life.

Our study shows that cervical spine arthritis is a serious and persistent manifestation of JIA with severe skeletal sequelae as shown by an increase in number of patients and number of anatomical sites with ankylosis, erosions and narrowing of cranio-cervical junction at follow-up. This is crucial and may include therapeutic implications, particularly because almost all of our patients needed treatment with biologic agents, including most of them requiring therapy intensification due to the diagnosis of cervical spine arthritis. This corroborates the findings of Lee who found that the use of TNF$\alpha$ inhibitors was an independent risk factor of structural spinal damage [6]. Furthermore, our study shows that MRI specific findings like hyperintensities, enhancement and malalignments allow early diagnosis -as indicated by a median disease duration of 1.7 years after diagnosis of JIA - and that these changes often decrease under therapy while in some patients osseous changes increase. The latter is highlighted by the fact that 6 out of 13 patients (46\%) showed ankylosis, erosions or narrowing of the spinal canal at the CCJ after a median disease durationof cervical spine arthritis of 2.1 years. Other studies 
Table 3 Number of sites and quality of MRI findings at diagnosis and follow-up (in brackets) in 13 patients

\begin{tabular}{|c|c|c|c|c|c|c|c|c|c|c|c|}
\hline \multirow[t]{2}{*}{ Qualitiy MRI findings } & \multicolumn{11}{|c|}{ Site } \\
\hline & AA & $A D$ & AO & $\mathrm{C} 2 / 3$ & $\mathrm{C} 3 / 4$ & $\mathrm{C} 4 / 5$ & $\mathrm{C} 5 / 6$ & $\mathrm{C} 6 / 7$ & Dens & Atlas & Sum \\
\hline Joint hyperintensity & $11(9)$ & $10(4)$ & $6(2)$ & $1(-)$ & - & - & - & - & - & - & $28(15)$ \\
\hline Joint enhancement & $12(7)$ & $12(10)$ & $7(2)$ & $1(-)$ & - & - & - & - & - & - & $32(19)$ \\
\hline Malalignment & $5(2)$ & $7(1)$ & $3(-)$ & - & - & $-(1)$ & $-(1)$ & $-(1)$ & - & - & $15(6)$ \\
\hline Ankylosis & - & - & $-(1)$ & $2(3)$ & - & $-(1)$ & $-(1)$ & $-(1)$ & - & - & $2(7)$ \\
\hline Erosion & - & - & - & - & - & - & - & - & $1(3)$ & $1(3)$ & $2(6)$ \\
\hline $\begin{array}{l}\text { Narrowing of the } \\
\text { spinal canal at CCJ }\end{array}$ & & & & & & & & & $3(4)$ & & $3(4)$ \\
\hline
\end{tabular}

Caption:

Hyperintensity (STIR see Methods) enhancement: pathological joint enhancement after gadolinium.

$A A$ atlanto-axial joint.

$A D$ atlanto-dental joint.

$A O$ atlanto-occipital joint.

$C$ facet joint of the cervical spine.

$\mathrm{CCJ}$ cranio-cervical junction.

reported spinal changes only after a median disease duration of 6-24 years using conventional radiography [9-13,24]. Although different imaging techniques, disease characteristics (eg. rheumatoid factor positivity) and duration of disease hamper direct comparison of published results, we think that MRI with its high sensitivity to synovial abnormalities and adjacent bone marrow edema allows diagnosis of cervical spine arthritis earlier than other imaging modalities. This view is supported by the fact that most malalignments were reversible under therapy, probably indicating that these MRI changes are precursors of radiographically documented fixed subluxations. Hence it might be prudent to monitor MRI findings indicative of arthritis in order not to miss transition into irreversible damage like ankylosis, erosions and narrowing of the spinal canal at the craniocervical junction.
Our study, in agreement with others, illustrates the importance of LROM as a leading clinical sign of cervical spine arthritis: $\mathrm{AA}$ and $\mathrm{AD}$ joints were most often affected and these joints account for the major mobility of the cervical spine [11]. Whereas LROM was found in all 13 patients at the time of diagnosis, while only a minority complained of pain indicating that patient history is not a sufficient criterion for cervical spine involvement; a thorough clinical examination is mandatory at every visit. A study based on x-ray findings confirmed a high percentage of asymptomatic patients [9]. While pain improved sufficiently under treatment, LROM was still present in 9 of our patients at follow-up. This persistence of LROM which has been described by others $[9,25]$ is indicative of severe long-term skeletal sequelae.

We believe that patients with osseous changes like ankylosis, erosion or narrowing of the spinal canal at

Table 4 Number of patients and quality of MRI findings at diagnosis and follow-up (in brackets)

\begin{tabular}{|c|c|c|c|c|c|c|c|c|c|c|c|c|c|c|c|c|}
\hline \multirow[t]{2}{*}{ Qualitiy MRI findings } & \multicolumn{16}{|c|}{ Site } \\
\hline & $\begin{array}{l}A D+ \\
A A+ \\
A O\end{array}$ & $\begin{array}{l}A D+ \\
A A\end{array}$ & $\begin{array}{l}\mathrm{AA}+ \\
\mathrm{AO}\end{array}$ & AA & AD & $\begin{array}{l}A D+ \\
A A+ \\
A Q+ \\
C 2 / 3\end{array}$ & $\mathrm{C} 2 / 3$ & $\begin{array}{l}\mathrm{C} 2 / 3+ \\
\mathrm{AO}\end{array}$ & $\begin{array}{l}\mathrm{C} 2 / 3+ \\
\mathrm{C} 4-7\end{array}$ & $\mathrm{C} 3 / 4$ & C4-7 & $\begin{array}{l}\mathrm{C} 4-7+ \\
\mathrm{AA}\end{array}$ & $\begin{array}{l}\text { Dens + } \\
\text { Atlas }\end{array}$ & Dens & Atlas & Sum \\
\hline Joint hyperintensity & $5(1)$ & $3(3)$ & $0(1)$ & $\begin{array}{c}2 \\
(4)\end{array}$ & $\begin{array}{c}1 \\
(0)\end{array}$ & $1(0)$ & - & - & - & - & $0 / 1$ & - & - & - & - & $\begin{array}{l}12 \\
(10)\end{array}$ \\
\hline Joint enhancement & $6(2)$ & $4(5)$ & - & $\begin{array}{c}1 \\
(0)\end{array}$ & $\begin{array}{c}1 \\
(3)\end{array}$ & $1(0)$ & - & - & - & $0(1)$ & - & - & - & - & - & $\begin{array}{l}13 \\
(11)\end{array}$ \\
\hline Malalignment & $3(0)$ & $1(0)$ & - & $\begin{array}{c}1 \\
(1)\end{array}$ & $\begin{array}{c}3 \\
(1)\end{array}$ & - & - & - & - & - & - & $0(1)$ & - & - & - & $8(3)$ \\
\hline Ankylosis & - & - & - & - & - & - & $2(1)$ & $0(1)$ & $0(1)$ & - & - & - & - & - & - & $2(3)$ \\
\hline Erosion & - & - & - & - & - & - & - & - & - & - & - & - & $0(2)$ & $1(1)$ & $1(1)$ & $2(4)$ \\
\hline $\begin{array}{l}\text { Narrowing of the } \\
\text { spinal canal at CCJ }\end{array}$ & & & & & & & & & & & & & & $3(4)$ & & $3(4)$ \\
\hline
\end{tabular}

Caption see Table 3. 
cranio-cervical junction should be advised to restrict excessive or sports activities involving the cervical spine. Narrowing of spinal canal at the cranio-cervical junction caused by hypertrophy of the dens was diagnosed in 4 patients at follow-up. Fortunately none of our patients developed neurological deficit, a poor prognostic factor in rheumatoid arthritis of adulthood: of 21 patients with myelopathy all became bedridden within three years of onset/diagnosis and one third died [26]. In rheumatoid arthritis with symptomatic cervical spine involvement there is also a strong correlation between the development of neurological dysfunction and MRI identification of atlanto-axial spinal canal stenosis [7]. Consequently in cases with neurological symptoms and/or basilar impression, a multidisciplinary approach with experienced MRI investigators and neurosurgeons seems reasonable, and such neurological findings are clearly of utmost importance to anesthetists, where intubation may be necessary for painful interventions such as joint injections or MRI under sedation.

In adult rheumatoid arthritis controversy exists as to whether to perform conventional radiographs or MRI for diagnosis of cervical spine arthritis $[7,8]$. Studies on imaging procedures in childhood report low sensitivity of radiography: in one study 15 of 29 patients revealed limited cervical spine motion whereas there was radiographic evidence of atlanto-axial subluxation in only 5 [25]. In another study of 20 patients, $65 \%$ had soft tissue involvement, pannus formation or erosions on the surface of atlanto-axial joints while only $20 \%$ had erosions on plain x-ray views [15]. Given the severity of changes seen in our patients at the onset of disease and the high prevalence of structural cervical spine changes, we would advocate MRI as the procedure of choice for the diagnosis and follow-up of cervical spine involvement in JIA. Only this technique enables a visualization of synovial thickening, increased joint fluid, spinal cord, brainstem and the relationship between occiput, atlas and axis [27]. With projection radiography it would probably not have been possible to monitor the extent of spinal involvement in our patients including those with multiple joint involvement. Moreover MRI reduces radiation exposure, which is especially important in young children. Clearly not all JIA patients need an MR examination of the cervical spine: patients with persistent oligoarthritis do not, or only rarely, develop cervical spine disease [3,11,28-33], however in polyarticular disease cervical spine involvement is frequent both in rheumatoid factor positive and negative patients [9,11]. Hence we would recommend MR imaging in the following situations: (1) signs and symptoms of cervical spine involvement, (2) rheumatoid factor positive and (3) rheumatoid factor negative polyarthritis or extended oligoarthritis with recalcitrant disease necessitating intensive therapy. In cases with narrowing of the spinal canal at cranio-cervical junction or clinically worsening courses, we would recommend control MRI in 6-9 monthly intervals (in milder cases 12 monthly) in order to consider options for treatment intensification.

For reasons of higher specificity as well as comparability of findings, classification criteria for MRI diagnosis of cervical spine involvement are necessary similar to those proposed for radiographic findings $[18,19,34]$. Regarding the MRI technical procedure, we would like to stress that pathological enhancement revealed additional sites indicating that it is reasonable to apply a contrast medium when performing cervical imaging in JIA patients.

Limitations of our study were the small number of patients and the retrospective study design applying data from medical records, although all patients were examined by the same two pediatric rheumatologists (T.H., J. M.). The lack of exact measurement tools for cervical spine movements in clinical practice might have led to imprecise findings, however all patients with LROM had asymmetry of cervical joint movement in our view, indicating unequivocal findings.

\section{Conclusion}

In conclusion this first MRI based follow-up study shows that cervical spine arthritis can follow a severe course of juvenile arthritis. While malalignments and inflammation sites decreased, osseous changes with erosions, ankylosis and narrowing of the cervical spine junction increased despite minor subjective complaints and treatment with biological agents. Close MRI monitoring of these patients appears to be a sensitive tool for early diagnosis and may help to detect further disease progression and complications.

\section{Competing interests}

The authors declare that they have no competing interests.

\section{Author's contribution}

All authors contributed to the drafting of the manuscript and approved the final version. TK provided the MRI images.

\section{Acknowledgment}

We acknowledge support by Deutsche Forschungsgemeinschaft and Open Access Publishing Fund of Tuebingen University.

We thank Dr. P. Ainsley and I. Maurath for linguistic assistance.

\section{Author details}

'Division of Pediatric Rheumatology, Children's Hospital, Olgahospital Stuttgart, teaching hospital of the University of Tuebingen, Bismarckstr. 8, 70176 Stuttgart, Germany. ${ }^{2}$ Radiologic Institute, Children's Hospital, Olgahospital Stuttgart, teaching hospital of the University of Tuebingen, Bismarckstr. 8, 70176 Stuttgart, Germany. ${ }^{3}$ Children's Hospital, Asklepios Klinik, Arnold-Janssenstr. 29, 53757 Sankt Augustin, Germany.

Received: 17 October 2013 Accepted: 28 February 2014

Published: 4 March 2014 


\section{References}

1. Neva MH, Kaarela K, Kauppi M: Prevalence of radiological changes in the cervical spine-a cross sectional study after 20 years from presentation of rheumatoid arthritis. J Rheumatol 2000, 27(1):90-93.

2. Halla JT, Hardin JG, Vitek J, Alarcon GS: Involvement of the cervical spine in rheumatoid arthritis. Arthritis Rheumatism 1989, 32(5):652-659.

3. Hensinger RN, DeVito PD, Ragsdale CG: Changes in the cervical spine in juvenile rheumatoid arthritis. J Bone Joint Surg Am 1986, 86(2):189-198.

4. Neva MH, Hakkinen A, Makinen H, Hannonen P, Kauppi M, Sokka T: High prevalence of asymptomatic cervical spine subluxation in patients with rheumatoid arthritis waiting for orthopaedic surgery. Annals Rheumatic Dis 2006, 65(7):884-888.

5. Kolen ER, Schmidt MH: Rheumatoid arthritis of the cervical spine. Seminars Neurol 2002, 22(2):179-186.

6. Lee JS, Lee S, Bang SY, Choi KS, Joo KB, Kim YB, Sung, L-Hoon I, Kim, Tae-Hwan: Prevalence and risk factors of anterior atlantoaxial subluxation in ankylosing spondylitis. J Rheumatol 2012, 39(12):2321-2326.

7. Narvaez JA, Narvaez J, Serrallonga M, De Lama E, de Albert M, Mast R, Nolla $J \mathrm{M}$ : Cervical spine involvement in rheumatoid arthritis: correlation between neurological manifestations and magnetic resonance imaging findings. Rheumatology (Oxford) 2008, 47(12):1814-1819.

8. Riew KD, Hilibrand AS, Palumbo MA, Sethi N, Bohlman HH: Diagnosing basilar invagination in the rheumatoid patient. The reliability of radiographic criteria. J Bone Joint Surg Am Vol 2001, 83-A 2:194-200.

9. Elhai M, Wipff J, Bazeli R, Freire V, Feydy A, Drape JL, Quartier P, Kahan A, Job-Deslandre C: Radiological cervical spine involvement in young adults with polyarticular juvenile idiopathic arthritis. Rheumatology (Oxford) 2013, 52(2):267-275

10. Kjellberg H, Pavlou I: Changes in the cervical spine of children with juvenile idiopathic arthritis evaluated with lateral cephalometric radiographs: a case control study. Angle Orthodontist 2011, 81(3):447-452.

11. Laiho K, Kauppi M: The cervical spine in patients with psoriatic arthritis. Annals Rheumatic Dis 2002, 61(7):650-652.

12. Laiho K, Hannula S, Savolainen A, Kautiainen H, Kauppi M: Cervical spine in patients with juvenile chronic arthritis and amyloidosis. Clinical Exper Rheumatol 2001, 19(3):345-348.

13. Espada G, Babini JC, Maldonado-Cocco JA, Garcia-Morteo O: Radiologic review: the cervical spine in juvenile rheumatoid arthritis. Semin Arthritis Rheum 1988, 17(3):185-195.

14. Younes M, Belghali S, Kriaa S, Zrour S, Bejia I, Touzi M, Golli M, Gannouni A, Bergaoui N: Compared imaging of the rheumatoid cervical spine: prevalence study and associated factors. Joint bone Spine revue du Rhumatisme 2009, 76(4):361-368.

15. Oren B, Oren H, Osma E, Cevik N: Juvenile rheumatoid arthritis: cervical spine involvement and MRI in early diagnosis. Turk J Pediatr 1996, 38(2):189-194.

16. Haapasaari J, Soini I, Kauppi M: MRI diagnosis and successful treatment of upper cervical spine synovitis in a patient with juvenile chronic arthritis. Clin Exp Rheumatol 2002, 20(2):256-257.

17. Hemke $R$, van Veenendaal $M$, van den Berg JM, Dolman KM, van Rossum MA, Maas M, Kuijpers TW: One-year followup study on clinical findings and changes in magnetic resonance imaging-based disease activity scores in juvenile idiopathic arthritis. J Rheumatol 2014, 41(1):119-127.

18. Kauppi M: A method for classification of the posterior atlanto-axial subluxation. Clinical Rheumatol 1994, 13(3):492-495.

19. Kauppi M, Sakaguchi M, Konttinen YT, Hamalainen M: A new method of screening for vertical atlantoaxial dislocation. J Rheumatol 1990, 17(2):167-172

20. Van Mameren H, Drukker J, Sanches H, Beursgens J: Cervical spine motion in the sagittal plane (I) range of motion of actually performed movements, an X-ray cinematographic study. European J Morphol 1990, 28(1):47-68.

21. Guzman J, Burgos-Vargas R, Duarte-Salazar C, Gomez-Mora P: Reliability of the articular examination in children with juvenile rheumatoid arthritis: interobserver agreement and sources of disagreement. J Rheumatol 1995, 22(12):2331-2336

22. Petty RE, Southwood TR, Manners P, Baum J, Glass DN, Goldenberg J, He X, Maldonado-Cocco J, Orozco-Alcala J, Prieur AM, Suarez-Almazor ME, Woo P: International league of associations for rheumatology classification of juvenile idiopathic arthritis: second revision, edmonton, 2001. J Rheumatol 2004, 31(2):390-392.
23. Hodgson RJ, O'Connor P, Moots R: MRI of rheumatoid arthritis image quantitation for the assessment of disease activity, progression and response to therapy. Rheumatology 2008, 47(1):13-21.

24. Enden K, Laiho K, Kautiainen H, Arkela-Kautiainen M, Belt E, Kauppi M: Subaxial cervical vertebrae in patients with juvenile idiopathic arthritis-something special? Joint Bone Spine 2009, 76(5):519-523.

25. Fried JA, Athreya B, Gregg JR, Das M, Doughty R: The cervical spine in juvenile rheumatoid arthritis. Clinical Orthopaedics Relat Res 1983, 179:102-106.

26. Sunahara N, Matsunaga S, Mori T, ljiri K, Sakou T: Clinical course of conservatively managed rheumatoid arthritis patients with myelopathy Spine (Phila Pa 1976) 1997, 22(22):2603-2607. discussion 8.

27. Oostveen JC, van de Laar MA: Magnetic resonance imaging in rheumatic disorders of the spine and sacroiliac joints. Seminars Arthritis Rheumatism 2000, 30(1):52-69.

28. Ornilla E, Ansell BM, Swannell AJ: Cervical spine involvement in patients with chronic arthritis undergoing orthopaedic surgery. Annals Rheumatic Dis 1972, 31(5):364-368.

29. Schaller J, Wedgwood RJ: Juvenile rheumatoid arthritis: a review. Pediatrics 1972, 50(6):940-953.

30. Thompson GH, Khan MA, Bilenker RM: Spontaneous atlantoaxial subluxation as a presenting manifestation of juvenile ankylosing spondylitis. A Case Report Spine 1982, 7(1):78-79.

31. Mitra S, Sharma J, Parmar VR: Atlanto-axial subluxation in JRA. Indian Pediatrics 1999, 36(11):1163-1166.

32. Breda L, Palazzi C, de Michele G, De Sanctis S, Chiarelli F: Spontaneous atlantoaxial subluxation as a presenting manifestation of juvenile ankylosing spondylitis in a female HLA-B27-negative patient. European $J$ Pediatrics 2005, 164(7):455-457.

33. Muscal E, Satyan KB, Jea A: Atlantoaxial subluxation as an early manifestation in an adolescent with undifferentiated spondyloarthritis: a case report and review of the literature. J Med Case Reports 2011, 5:275.

34. Laiho K, Kauppi M, Konttinen YT: Why atlas, why not heracles: reflections on the rheumatoid cervical spine. Semin Arthritis Rheum 2005, 34(4):637-641.

doi:10.1186/1546-0096-12-9

Cite this article as: Hospach et al:: Cervical spine involvement in patients with juvenile idiopathic arthritis - MRI follow-up study. Pediatric Rheumatology 2014 12:9.

\section{Submit your next manuscript to BioMed Central and take full advantage of:}

- Convenient online submission

- Thorough peer review

- No space constraints or color figure charges

- Immediate publication on acceptance

- Inclusion in PubMed, CAS, Scopus and Google Scholar

- Research which is freely available for redistribution 